\title{
Volatility Transmission between Islamic and Conventional Equity Markets: Evidence from Causality-in-Variance Test
}

Saban Nazlioglu*, Shawkat Hammoudeh** and Rangan Gupta***

\begin{abstract}
:
This paper examines whether a volatility/risk transmission exists between the Dow Jones Islamic stock and three conventional stock markets for the U.S., Europe, and Asia during the pre- and the in- and post-2008 crisis periods. It also explores the volatility spillover dynamics between those markets and U.S. Monetary policy, oil prices, global financial risk and uncertainty factors. The recently developed Hafner and Herwartz (2006)'s causality-in-variance test provides evidence of risk transfers between these seemingly different equity markets, indicating a contagion between them. The volatility structure of these markets is dominated by short-run volatility in the first period and by high long-run volatility in the second period. The volatility impulse response analysis indicates a similar volatility transmission pattern although it is characterized by a more volatile and short-lived structure in the second period. It also appears that the Islamic equity market responds to shocks from risk factors and not from the oil price and the U.S. economic policy uncertainty index during both periods.
\end{abstract}

Keywords: Islamic and conventional equity markets, volatility spillover.

JEL classification: $\mathrm{C}_{32}$; 58 ; G1

\section{Introduction}

The fast growth of investments in the Islamic finance industry has rekindled new interest in doing research on Islamic financial markets. The markets that follow the Sharia -based principles have grown 500\% in the last five years and reach \$ 1.6 trillion in 2013 (Hammoudeh et al., 2013) from \$1.46 in 2012 (Vizcaino, 2013). This fast growth leads several governments and policy makers to identify Islamic finance as a key global investment area in the world. For instance, at the $5^{\text {th }}$ Izmir Economic Congress which was held in 2013, the president of the World Bank strongly lent his support

\footnotetext{
* Department of Econometrics, Pamukkale University, Denizli-Turkey. Email: snazlioglu@pau.edu.tr.

** Corresponding author. LeBow College of Business, Drexel University, Philadelphia, USA. Email: hammousm@drexel.edu.

Department of Economics, University of Pretoria, Pretoria, South Africa. Email: rangan.gupta@up.ac.za.
} 
to Islamic finance. In London in the same year, the British prime minister announced that a new Islamic Index will be created on the London Stock Exchange and that there are real plans afoot for the UK Government to issue Islamic bonds known as sukuks ${ }^{1}$. The government of Dubai also declared its support for Islamic finance earlier this year. London, Kuala Lumpur and Dubai are currently competing for pre-eminence as the Islamic finance center. In Turkey which is one of the most growing emerging markets during the last decade, the deputy prime minister for Economic and Financial Affairs, Republic of Turkey) emphasized the important role of sukuk in financing current account deficit.

Weathering the severe recent global financial crisis, the Islamic finance industry has emerged as an alternative financial architecture that can probably endure financial crises better than the conventional counterparts. This financial crisis has increased volatility, volatility spillover and contagion among global financial markets including equity markets. Some argue that Islamic equity markets are not supposed to transmit risk and volatility to and from conventional equity markets because they are fundamentally different (Dridi and Hassan, 2010; Chapra, 2008; Dewi and Ferdian, 2010). As discussed in Rehman (2009), Islamic economic and financial principles bear relevance to the recent global turbulence and to the design of the post 2008 crisis financial order. The Islamic and conventional markets differ in several ways. The Islamic markets prefer growth and small cap stocks, while conventional markets favor value and mid cap stocks. Furthermore, Islamic finance restricts investments in some industries such alcohol, tobacco, rearms, gambling, nuclear power and militaryweapons activities. It also restricts speculative financial transactions such as financial derivatives which have no underlying real transactions like futures and options, government debt issues with a fixed coupon rate, and hedging by forward sale, interest-rate swaps and any other transactions involving items not physically in the ownership of the seller (e.g., short sales).

In this paper, we examine volatility or risk transmissions between the Dow Jones Islamic equity market (DJIM) and three major global conventional equity markets over the pre-crisis and the in- and post-crisis subperiods. The conventional regional markets include the U.S., European and Asian markets. To explore the risk transmission, we rely on the causality-in-variance test developed by

\footnotetext{
${ }^{1}$ Sukuk refers to the Islamic equivalent of bonds that are structured to comply with the Islamic law and investment principles in which any charge or pay for interest is prohibited.
} 
Hafner and Herwartz (2006). These authors contend that their approach overcomes the shortfalls of the former methods, is more robust against leptokurtic innovations in small samples, and is very practical for empirical applications. In addition to the causality-in-variance analysis, we derive the volatility impulse response functions to compare how the Islamic and conventional equity markets respond to short-run temporary shocks in volatility.

The empirical results provide strong evidence that the volatility spillover test shows evidence of risk transfer between the Islamic equity market and the three major global conventional equity markets, hence implying a contagion between these global equity markets. They also show that the volatility structure of the equity markets is dominated by the short-run volatility in the pre-crisis period. However, in the in- and post-crisis period this process is found to be affected by the high longrun volatility. This implies that investors respond quickly to risk perceptions with portfolio diversification, which in turn leads to more volatile dynamics in the equity markets. The volatility impulse response analysis also indicates that although the volatility transmission mechanism between these equity markets seems to have similar patterns in the two sub-periods, the mechanism has a more volatile and short-lived structure in the second (in- and post crisis) than the first (pre-crisis) period.

The use of causality-in-variance tests is entirely justified by the fact that the economic and financial time series tend to quickly interact with each other and thereby show a volatility transmission structure. By comparing volatility spillovers during two different periods such as the pre- and the inand post- 2007/2008 crisis periods, the results should clearly indicate how the DJIM compared to the conventional equity markets stands the test of time. It is useful to figure out if the volatility transmission exists and to understand the direction of the risk spillover between the Islamic equity markets and each of the conventional markets. It will also be interesting to discern how the Islamic market volatility responds to the volatility shocks from global influential factors such as the U.S. monetary policy (as defined by the U.S. federal funds rate), the U.S. implied volatility risk VIX, the U.S. economic policy uncertainty index and oil prices.

While the literature on Islamic banks is adequate and well-established, it is limited on the Islamic stock market and more so when it comes to volatility than returns. The general literature also is mixed on the link between the conventional stock and bond markets. Based on the empirical evidence, 
this literature can be classified into three strands. One strand demonstrates a unidirectional volatility spillover effect from the stock market to the bond market (see Fang et al., 2007, among others). A second strand shows a unidirectional volatility transmission from the bond market to the stock market (see Kim et al., 2001; Kim et al., 2006; Dean et al., 2010, among others). The third strand reports bidirectional volatility spillover between those asset markets (Andersen et al., 2005; Cappiello et al., 2006; Chuliá and Torró, 2008, among others). However, Steeley (2006) reports no volatility spillover between these markets,

Most of the Islamic literature deals with Islamic banks and equity returns. Dealing with causal linkages between the Islamic and conventional equity markets, Ajmi et al. (2013) find evidence of significant linear and nonlinear causality between those stock markets but more strongly from the Islamic stock market to the other markets. These authors also report strong causality between the Islamic stock market and global financial and risk factors. This evidence leads to the rejection of the hypothesis of decoupling of the Islamic stock market from its conventional counterparts.

In addition to exploring the causal linkages between the Islamic and conventional equity markets, some attention is paid to examining volatility structure. Kassab (2013) explores the persistence of volatility of the Islamic (DJIM) and conventional (S\&P 500 index) markets, using the GARCH model. This author shows that the volatility persistence of both markets is highly significant, with the DJIM index being less volatile than the conventional index in the long run and presenting less risk at crisis periods. On the impact of global factors, Yousef and Majid (2007) examine the extent to which volatility in the Islamic and conventional stock markets in Malaysia is sensitive to the volatility in the U.S. interest rates. They find that the U.S. interest rate volatility affects the conventional stock market volatility but not the Islamic stock market volatility, implying that the stabilizing interest rate would have insignificant impact on the volatility of the Islamic stock markets. On the diversification benefits of combining Islamic and conventional assets, Akhtar et al. (2011) show that by including at least one Islamic asset in the portfolio, it would lower the volatility linkages rise by up to 7.17 percentage points, after controlling for the country and asset-specific characteristics. These authors also indicate that this result is stronger during financial crises and is not driven by the oil sector. More recently, Chau et al. (2013) examine the impact of this political uncertainty on stock market volatility in 
MENA countries, using a variety of GARCH models. They provide evidence that political turmoil has increased stock market volatility, mainly through the Islamic indices.

To our knowledge, there are few studies that deal with volatility transmission. Kim and Kang (2012) analyze the transmission mechanism of volatility between Islamic stock, Sukuk and the government bond markets in Malaysia, as representatives of Islamic finance, in recognition of the crucial roles they play in portfolio and risk management. By utilizing a VAR-bivariate GARCH model during the recent global financial crisis and a VECM-bivariate GARCH model thereafter, those authors find a unidirectional volatility spillover from the stock market to the bond market in Malaysia during the recent global financial crisis, but find no clear volatility spillover from the bond market to the stock market volatility during periods of stability. However, they find that the bond market has a more dominant role in price discovery than the stock market.

As this literature review shows, no doubt that there is a growing focus on the linkages between the Islamic and conventional finance markets but the empirical conclusions seem to be mixed. These mixed results can be attributed to time periods, data sets, frequencies, methodologies and model descriptions. Even though there is a consensus on the relevance of Islamic finance to conventional finance, the literature is limited on the risk transmission between these markets. Furthermore, the relations between financial markets can change due to the effect of global crises. This paper attempts to fill the gap in the literature regarding the volatility transmissions between Islamic and conventional stock markets as well as focusing on these linkages in the pre-crisis period and in the in- and post-crisis period.

To best of our knowledge, this is the first study to apply the causality-in-variance test developed by Hafner and Herwartz (2006) to the Islamic and conventional markets. This method is superior to the causality-in-variance test developed by earlier in the literature. This paper also utilizes impulse response functions in order to identify temporal volatility transmission dynamics between the markets under consideration 
The rest of the paper is organized as follows: The econometric methodology is outlined in section 3, followed by data definition in Section 3. Inferences from the discussion of the empirical results are provided in Section 4. Section 5 is devoted to give a brief summary and discuss policy implications.

\section{Econometric Methodology}

This study employs the Lagrange multiplier-based causality-in-variance test, which was recently developed by Hafner and Herwartz (2006), to determine the volatility spillovers between the Islamic and conventional stock markets. Previously, Cheung and Ng (1996) and Hong (2001) developed the causality-in-variance test based on the cross-correlation functions (CCF) of the standardized residuals obtained from the estimates of the univariate general autoregressive conditional heteroscedasticity (GARCH) to examine the volatility spillovers between any two series. The corresponding CCF-based Portmanteau test is likely to suffer from significant oversizing in small samples when the volatility processes are leptokurtic (Hafner and Herwartz, 2006: 140). In addition, the results from the CCF-based testing approach are sensitive to the orders of leads and lags, which in turn questions the robustness of the findings.

The volatility spillover test of Hafner and Herwartz (2006) that is based on the Lagrange multiplier (LM) principle overcomes the shortfalls of the Cheung and Ng (1996) method and is very practical for empirical analysis. Furthermore, the Monte Carlo experiment carried out in Hafner and Herwartz (2006) indicates that the LM approach is more robust against the leptokurtic innovations in small samples and that the gain from carrying the LM-based test increases with the sample size. The results further show that an inappropriate lead and lag order choice in the CCF test distorts its performance, thereby leading to the risk of selecting the wrong order for the CCF statistic. In what follows, we briefly explain the details of the Hafner and Herwartz (2006) causality-in-variance test.

In the Hafner and Herwartz (2006) approach, testing for the in-variance causality is based on estimating univariate GARCH models. To test the null hypothesis of the non-causality in variance between returns $i$ and $j$, the following model is put forth as: 
$\left.\varepsilon_{i t}=\xi_{i t} \sqrt{\sigma_{i t}^{2}\left(1+z_{j}^{\prime} \pi\right.}\right), \quad z_{j t}=\left(\varepsilon_{j t-1}^{2}, \sigma_{j t-1}^{2}\right)^{\prime}$

where $\xi_{i t}$ and $\sigma_{i t}^{2}$ are respectively the standardized residuals and the conditional variance (volatility) for return i; $\varepsilon_{j t-1}^{2}$ and $\sigma_{j t-1}^{2}$ are respectively the squared disturbance term and the conditional variance for return j. In this specification, the null hypothesis of the non-causality in variance specified by $H_{0}: \pi=0$ is tested against the alternative hypothesis of causality in variance denoted by $H_{1}: \pi \neq 0$.

The score of the Gaussian log-likelihood function of $\varepsilon_{i t}$ is given by $x_{i t}\left(\xi_{i t}^{2}-1\right) / 2$ where $x_{i t}$ are the derivatives of the likelihood function with respect to the parameters in the GARCH model. Hafner and Herwartz (2006) propose the following LM test in order to determine the volatility transmission between the series:

$$
\lambda_{L M}=\frac{1}{4 T}\left(\sum_{t=1}^{T}\left(\xi_{i t}^{2}-1\right) z_{j t}^{\prime}\right) V\left(\theta_{i}\right)^{-1}\left(\sum_{t=1}^{T}\left(\xi_{i t}^{2}-1\right) z_{j t}\right)
$$

where

$V\left(\theta_{i}\right)=\frac{\kappa}{4 T}\left(\sum_{t=1}^{T} z_{j t} z_{j t}^{\prime}-\sum_{t=1}^{T} z_{j t} x_{i t}^{\prime}\left(\sum_{t=1}^{T} x_{i t} x_{i t}^{\prime}\right)^{-1} \sum_{t=1}^{T} x_{i t} z_{j t}^{\prime}\right), \quad \kappa=\frac{1}{T} \sum_{t=1}^{T}\left(\xi_{i t}^{2}-1\right)^{2}$

The asymptotic distribution of the test statistic in Equation (3) depends on the number of misspecification indicators in $z_{j t}$. Since there are two misspecification indicators in $\lambda_{L M}$, the test has an asymptotic chi-square distribution with two degrees of freedom.

In addition to testing for the causality in variance, this study employs the impulse-response analysis in order to determine how the volatility of the Islamic and conventional stock markets responds to a shock from each other. In this regard, we utilize the generalized impulse-response method advocated by Koop et al. (1996), and Pesaran and Shin (1998) which are superior to the traditional approach because it is not subject to the orthogonality critique arising from the Cholesky ordering. Moreover, the results from the generalized impulse response functions are not sensitive to the ordering of variables in the vector autoregressive (VAR) system. 


\section{Data description}

The data set includes daily observations from January 04, 1999 to September 20, 2013 for the Dow Jones Islamic stock (DJIM) index and the three conventional stock markets for the U.S. (SPA500), Europe (SPEU) and Asia (SPAS50TR). It also includes global explanatory variables that are related to those four stock markets. These global variables include the Brent oil price which is a better measure of the oil market scarcity and sensitivity than the WTI, the U.S. economic uncertainty index (US policy) which is responsive to economic and political news in the United States (Baker et al., 2013), a measure of volatility and fear in the U.S. equity market (VIX) to capture anxiety in the world markets, and the federal funds rate (FFR) to arrest the impact of monetary policy on the equity markets under consideration. There is a stronger focus in this study on the United States because more than 60\% of the DJIM index are stocks from the United States and the rest are from Europe and East Asia. To our knowledge, the number of stock indexes from the Moslem countries is minimal because most of those countries do not have Islamic sharia-compliant stock markets. The four stock indexes are from Bloomberg, the economic policy incertainty index is obtained from www.policyuncertainty.com, while the remainder of the series comes from the FRED database of the St. Louis Federal Reserve.

Table 1 reports the descriptive statistics for the return series of the equity markets under consideration as well as the global financial indexes for three samples: the full sample, the pre-crisis sample and the in- and post- crisis sample. Among all those four stock markets, the Asian stock market yields the highest average return over the full and the pre-crisis periods under consideration, followed by the Islamic market. Interestingly, the return average for the Islamic market during the in- and post crisis period comes third after the Asian and U.S. markets. It is however negative for the European area during the three periods. The average returns for all markets are generally lower during the in- and post- crisis period than in the pre-crisis period, clearly demonstrating that the Islamic and conventional markets all have been affected by the crisis and its aftermath. It is worth noting that the oil price return is greater than the index returns of the four stock markets in almost all periods. This result underlines the importance of investing in the oil market over the equity markets, regardless of locations and time periods. 
In terms of volatility as defined by the standard deviation, the U.S. economic policy uncertainty index has by far the highest volatility, while the Islamic stock market has the lowest during the three periods as also provided by figure 1 . These facts as well as the ones indicated above obviously show that the Islamic market while is affected by the crisis and its aftermath, it is affected less than the conventional markets by the crisis. They also demonstrate the unusual volatility of the U.S. economic policy index which is news based. The volatility of the oil price return is much higher than the volatility of the Islamic and conventional stock markets but much lower than the volatility of the U.S. economic policy price index. The oil volatility is similar to the volatility of the federal funds rate.

As it is well known, skewness is a simple measure of asymmetry and kurtosis is a measurement for peaked or flatted distribution relative to a normal distribution. For the full sample, we observe that all the variables but FFR and VIX are skewed to the left and have excess kurtosis with the exception of U.S. economic policy, indicating the presence of asymmetry and non-normal distribution. This stylized fact is also supported by the Jarque-Bera statistic which rejects the null hypothesis of normality.
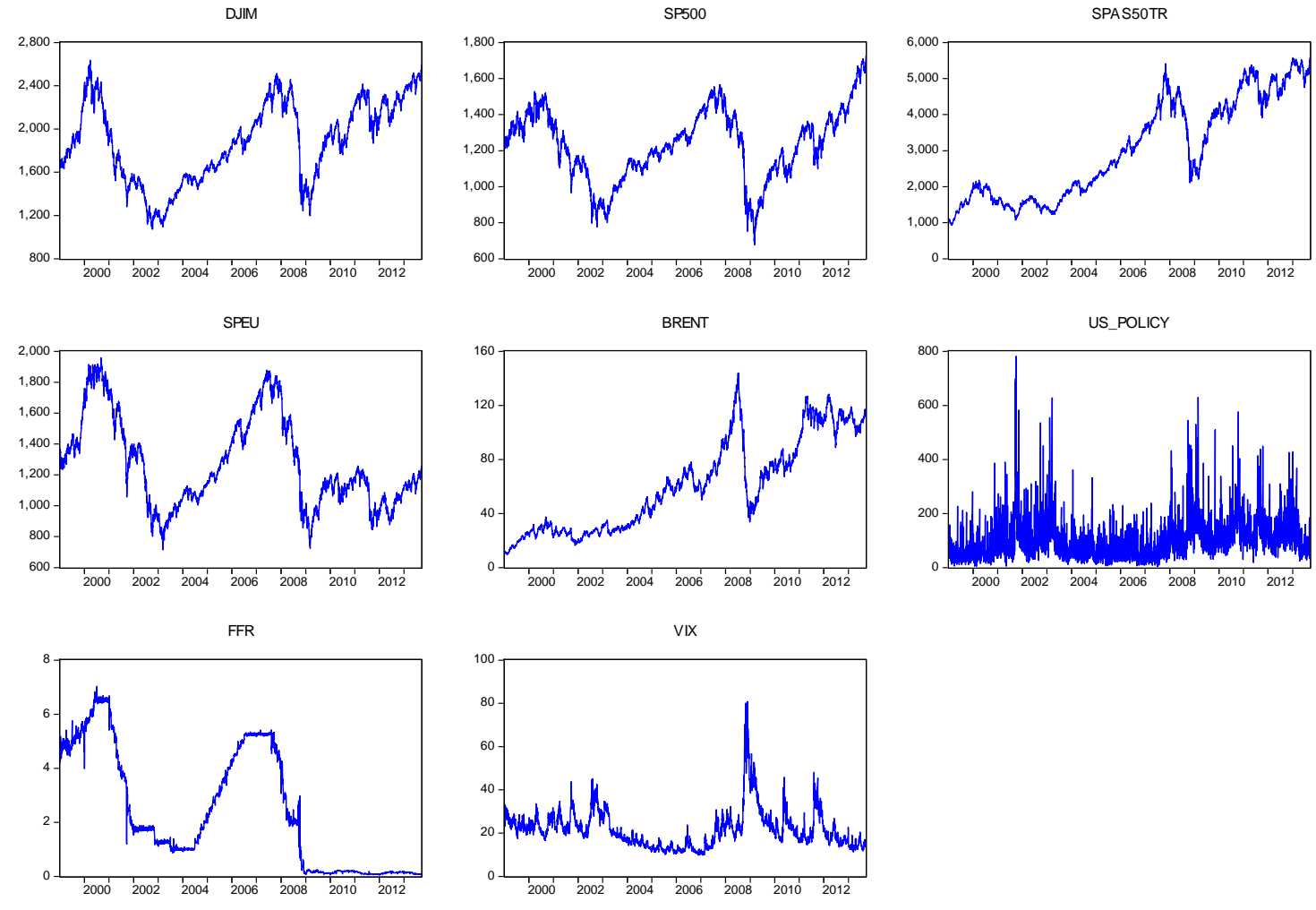

Figure 1: The series in the logarithmic form 
Table 1: Descriptive statistics for return series

\begin{tabular}{|c|c|c|c|c|c|c|c|c|}
\hline $\begin{array}{c}\text { Panel A: Full sample } \\
\text { O4 January } 1999 \\
\text { 20 September } 2013 \\
\end{array}$ & DJIM & SP5Oo & SPAS50TR & SPEU & BRENT & US policy & FFR & VIX \\
\hline Mean & 0.00012 & 0.00009 & 0.00044 & -0.00001 & 0.00060 & 0.00021 & -0.00105 & -0.00018 \\
\hline Median & 0.00056 & 0.00020 & 0.00060 & 0.00018 & 0.00040 & 0.00023 & 0.00000 & -0.00241 \\
\hline Maximum & 0.09775 & 0.10957 & 0.13303 & 0.10126 & 0.18130 & 3.13497 & 0.87547 & 0.49601 \\
\hline Minimum & -0.08186 & -0.09470 & -0.08921 & -0.08153 & -0.19891 & -2.75645 & -0.78846 & -0.35059 \\
\hline Std. Dev. & 0.01104 & 0.01289 & 0.01443 & 0.01426 & 0.02280 & 0.63098 & 0.07780 & 0.06176 \\
\hline Skewness & -0.29369 & -0.15494 & -0.12498 & -0.06147 & -0.27688 & -0.02503 & 0.14496 & 0.62585 \\
\hline Kurtosis & 9.44802 & 10.70136 & 8.09765 & 7.46360 & 8.40246 & 3.67452 & 32.41563 & $7 \cdot 35161$ \\
\hline Jarque-Bera & $\begin{array}{c}6705.769 \\
0.0000\end{array}$ & 9500.174 & $\begin{array}{c}4166.677 \\
0.0000\end{array}$ & $\begin{array}{c}3188.557 \\
0.0000\end{array}$ & $\begin{array}{c}4712.770 \\
0.0000\end{array}$ & $\begin{array}{l}73.178 \\
0.0000\end{array}$ & $\begin{array}{l}138386 \\
0.0000\end{array}$ & $\begin{array}{c}3279.672 \\
0.0000\end{array}$ \\
\hline $\begin{array}{l}\text { Probability } \\
\text { Observations }\end{array}$ & $\begin{array}{c}0.0000 \\
3839\end{array}$ & $\begin{array}{c}0.0000 \\
3838\end{array}$ & $\begin{array}{c}0.0000 \\
3839\end{array}$ & $\begin{array}{c}0.0000 \\
3838\end{array}$ & 3835 & 3839 & 3838 & 3839 \\
\hline \multicolumn{9}{|l|}{$\begin{array}{c}\text { Panel B: Subsample-I } \\
\text { O4 January } 1999 \\
\text { 31 December } 2007\end{array}$} \\
\hline Mean & 0.00016 & 0.00008 & 0.00066 & 0.00013 & 0.00092 & 0.00032 & -0.00021 & -0.00006 \\
\hline Median & 0.00049 & 0.00001 & 0.00079 & 0.00040 & 0.00102 & -0.00048 & 0.00000 & -0.00080 \\
\hline Maximum & 0.04464 & 0.05573 & 0.05731 & 0.06392 & 0.12853 & 3.13497 & 0.62355 & 0.49601 \\
\hline Minimum & -0.04823 & -0.06005 & -0.08921 & -0.06791 & -0.19891 & -2.75645 & -0.53298 & -0.29987 \\
\hline Std. Dev. & 0.00970 & 0.01095 & 0.01310 & 0.01282 & 0.02302 & 0.70611 & 0.04017 & 0.05607 \\
\hline Skewness & -0.11228 & 0.08419 & -0.26818 & -0.16641 & -0.45300 & 0.01466 & 0.22571 & 0.51188 \\
\hline Kurtosis & 4.86812 & $5 \cdot 30258$ & 5.46770 & 6.15243 & 7.08415 & $3 \cdot 32753$ & 54.55202 & $7 \cdot 43220$ \\
\hline Jarque-Bera & 346.063 & 521.027 & 623.373 & 982.251 & 1710.735 & 10.57027 & 259801.4 & 2022.687 \\
\hline Probability & 0.00000 & 0.00000 & 0.00000 & 0.00000 & 0.00000 & 0.00507 & 0.00000 & 0.00000 \\
\hline Observations & 2346 & 2346 & 2346 & 2346 & 2346 & 2346 & 2346 & 2346 \\
\hline \multicolumn{9}{|l|}{$\begin{array}{l}\text { Panel C: Subsample-II } \\
\text { O1 January } 2008 \\
\text { 20 September } 2013\end{array}$} \\
\hline Mean & 0.00005 & 0.00011 & 0.00011 & -0.00023 & 0.00011 & 0.00004 & -0.00236 & -0.00036 \\
\hline Median & 0.00063 & 0.00045 & 0.00018 & 0.00000 & 0.00009 & 0.02633 & 0.00000 & -0.00495 \\
\hline Maximum & 0.09775 & 0.10957 & 0.13303 & 0.10126 & 0.18130 & 1.62530 & 0.87547 & 0.40547 \\
\hline Minimum & -0.08186 & -0.09470 & -0.08586 & -0.08153 & -0.16832 & -1.98698 & -0.78846 & -0.35059 \\
\hline Std. Dev. & 0.01286 & 0.01545 & 0.01631 & 0.01626 & 0.02246 & 0.49042 & 0.11418 & 0.06980 \\
\hline Skewness & -0.39512 & -0.28025 & 0.01749 & 0.03679 & 0.01846 & -0.20705 & 0.13287 & 0.70137 \\
\hline Kurtosis & 10.70337 & 11.22411 & 9.21478 & 7.61525 & 10.73492 & 3.43047 & 16.68254 & 6.73860 \\
\hline Jarque-Bera & 3730.408 & 4224.238 & 2402.778 & 1324.521 & 3711.97 & 22.19465 & 11642.72 & 991.901 \\
\hline Probability & 0.00000 & 0.00000 & 0.00000 & 0.00000 & 0.00000 & 0.00002 & 0.00000 & 0.00000 \\
\hline Observations & 1493 & 1492 & 1493 & 1492 & 1489 & 1493 & 1492 & 1493 \\
\hline
\end{tabular}

The different data characteristics provided by the descriptive statistics for the pre- and the inand post-crisis periods lead to the question of whether the correlations among the returns of the variables vary across the sub-periods. At first glance, the correlation coefficients in Table 2 confirm that the correlations among the return series are stronger in the in- and post-crisis period than in the pre-crisis period. The Islamic stock return has the strongest correlation with the U.S. stock market, 
followed by the European market over the three periods under consideration. More than $60 \%$ of the stocks in the DJIM index are American stocks. The correlation results support the well-established fact that the financial asset returns' correlations increased during the financial stress. This fact states that the Islamic stock index return has significantly higher correlations with the conventional stock index returns during the in- and post-crisis period, compared to the pre-crisis period. This historical fact is evidence that the Islamic stock market has been affected by the financial crisis and its aftermath, as have been case for the conventional markets.

Table 2: Correlation matrix for return series

\begin{tabular}{|c|c|c|c|c|c|c|c|c|}
\hline $\begin{array}{c}\text { Panel A: Full sample } \\
\text { O4 January } 1999 \\
\text { 20 September } 2013\end{array}$ & DJIM & $\mathrm{SP}_{500}$ & SPAS50TR & SPEU & BRENT & US policy & FFR & VIX \\
\hline DJIM & 1.0000 & & & & & & & \\
\hline $\mathrm{SP}_{500}$ & 0.8852 & 1.0000 & & & & & & \\
\hline SPAS5OTR & 0.4273 & 0.1889 & 1.0000 & & & & & \\
\hline SPEU & 0.7510 & 0.5793 & 0.3830 & 1.0000 & & & & \\
\hline BRENT & 0.2169 & 0.1034 & 0.1330 & 0.1785 & 1.0000 & & & \\
\hline US policy & 0.0110 & 0.0190 & 0.0077 & 0.0017 & 0.0157 & 1.0000 & & \\
\hline FFR & -0.0434 & -0.0518 & -0.0407 & -0.0314 & -0.0017 & -0.0425 & 1.0000 & \\
\hline VIX & -0.6722 & -0.7458 & -0.1350 & -0.4522 & -0.0782 & -0.0372 & 0.0418 & 1.0000 \\
\hline $\begin{array}{c}\text { Panel B: Subsample-I } \\
\text { O4 January } 1999 \\
\text { 31 December } 2007\end{array}$ & DJIM & $\mathrm{SP}_{500}$ & SPAS50TR & SPEU & BRENT & US policy & FFR & VIX \\
\hline DJIM & 1.0000 & & & & & & & \\
\hline $\mathrm{SP}_{5} \mathrm{OO}$ & 0.8855 & 1.0000 & & & & & & \\
\hline SPAS5OTR & 0.3330 & 0.1133 & 1.0000 & & & & & \\
\hline SPEU & 0.6812 & 0.5128 & 0.3317 & 1.0000 & & & & \\
\hline BRENT & 0.0268 & -0.0398 & 0.0118 & -0.0120 & 1.0000 & & & \\
\hline US policy & 0.0143 & 0.0172 & 0.0159 & 0.0023 & 0.0246 & 1.0000 & & \\
\hline FFR & -0.0339 & -0.0149 & -0.0526 & -0.0448 & 0.0250 & -0.0364 & 1.0000 & \\
\hline VIX & -0.6639 & -0.7438 & -0.0859 & -0.3946 & 0.0257 & -0.0503 & 0.0482 & 1.0000 \\
\hline $\begin{array}{c}\text { Panel C: Subsample-I } \\
\text { O1 January } 2008 \\
\text { 20 September } 2013\end{array}$ & DJIM & $\mathrm{SP}_{500}$ & SPAS50TR & SPEU & BRENT & US-Policy & FFR & VIX \\
\hline DJIM & 1.0000 & & & & & & & \\
\hline $\mathrm{SP}_{5} \mathrm{OO}$ & 0.8857 & 1.0000 & & & & & & \\
\hline SPAS5OTR & 0.5176 & 0.2574 & 1.0000 & & & & & \\
\hline SPEU & 0.8167 & 0.6394 & 0.4339 & 1.0000 & & & & \\
\hline BRENT & 0.4538 & 0.2710 & 0.2918 & 0.4238 & 1.0000 & & & \\
\hline US policy & 0.0067 & 0.0247 & -0.0062 & 0.0008 & -0.0041 & 1.0000 & & \\
\hline FFR & -0.0513 & -0.0699 & -0.0402 & -0.0289 & -0.0176 & -0.0668 & 1.0000 & \\
\hline VIX & -0.6808 & -0.7503 & -0.1849 & -0.5098 & -0.2143 & -0.0175 & 0.0435 & 1.0000 \\
\hline
\end{tabular}


It is worth noting that DJIM has a negative and relatively high correlation with VIX for the three periods as shown in Table 2. This is the standard case between the U.S. S\&P 500 index and VIX which represents fear and anxiety in the markets. The negative correlation with VIX also holds for SPEU and SPAS50TR over the periods. As expected, the strongest negative correlation between VIX and the three markets is with the U.S. S\&P 500 index, followed by DJIM over those periods. The correlations with SPEU and SPAS50TR vary over the three periods which has to do with the world crises. This means an increase in fear in the U.S. stock market is reflected fairly well in DJIM but to a lower degree in the European and Asian markets. On the other hand, the correlations between DJIM and FFR and U.S. economic policy uncertainty are relatively very small for all three periods.

\section{Empirical results}

In order to examine the volatility spillover amongst the equity markets as well as FFR and VIX, we first estimate the univariate $\operatorname{GARCH}(1,1)$ models $^{2}$. Table 4 reports the results for the variance equations of the GARCH estimations for the full and the sub-samples. Before proceeding to the inferences from the estimation, one needs to check whether the stability conditions (intercept $\omega>0$, the ARCH parameter $\alpha \geq 0$, the GARCH parameter $\beta \geq 0$, and $\alpha+\beta<1$ ) of the GARCH model are satisfied. It is clear that the estimated GARCH models for all the variables except FFR satisfy the stability conditions. For FFR, the estimation satisfies these conditions in the in- and post-crisis period. Therefore, one can proceed to draw some inferences.

The positive coefficients in the variance equations signify the importance of the conditional variance (volatility) process of the variables. The volatility process of the alternative stock returns (DJIM, SP500, SPAS50TR, and SPEU) seems to be very similar. However, it varies slightly from the pre-crisis period to the in- and post-crisis period. Specifically, while the ARCH parameter appears to increase in the in- and post-crisis period, the GARCH parameter is higher in the pre-crisis period than that in the in- and post-crisis period. The degree of persistence $(\alpha+\beta)$ in both periods indicates the

\footnotetext{
2 It is worthwhile noting that the GARCH model assumes a stationary series. In order to examine the unit root properties of the variables in question, we apply the ADF test developed by Dickey and Fuller (1979) and DickeyFuller GLS (DF-GLS) developed by Elliott et al. (1996). The results show that all the return series are stationary. To save space, the results for unit root analysis are not reported here, but available upon request.
} 
persistence of the volatility shocks, implying a fair amount of persistence of the impact of the volatility shocks on the returns is there.

As stated earlier, we pay a special attention to the global explanatory variables. These global variables (BRENT, US policy, FFR, and VIX) have a different volatility path, compared to the stock markets. For the oil returns, while the ARCH effect is smaller in the in- and post-crisis period, the GARCH effect is higher in the in- and post-crisis period. For the other global variables -US policy, FFR, and VIX- the ARCH effect increases and the GARCH considerably decreases in the in- and post-crisis

Table 3: Results for variance equations

\begin{tabular}{|c|c|c|c|c|c|c|}
\hline \multirow[b]{2}{*}{ DJIM } & \multicolumn{2}{|c|}{$\begin{array}{c}\text { Full sample } \\
\text { O4 January } 1999 \\
\text { 20 September } 2013\end{array}$} & \multicolumn{2}{|c|}{$\begin{array}{c}\text { Subsample-I } \\
\text { O4 January } 1999 \\
\text { 31 December } 2007\end{array}$} & \multicolumn{2}{|c|}{$\begin{array}{c}\text { Subsample-II } \\
\text { o1 January 2008 } \\
\text { 20 September } 2013\end{array}$} \\
\hline & Coefficient & $\mathrm{p}$-value & Coefficient & p-value & Coefficient & p-value \\
\hline$\omega$ & $1.05 \mathrm{E}-06$ & 0.0000 & $5.65 \mathrm{E}-07$ & 0.0003 & $1.90 \mathrm{E}-06$ & 0.0001 \\
\hline$\alpha$ & 0.072851 & 0.0000 & 0.051753 & 0.0000 & 0.096522 & 0.0000 \\
\hline$\beta$ & 0.917384 & 0.0000 & 0.941779 & 0.0000 & 0.889768 & 0.0000 \\
\hline \multicolumn{7}{|l|}{$\mathrm{SP}_{500}$} \\
\hline$\omega$ & $1.39 \mathrm{E}-06$ & 0.0000 & $8.35 \mathrm{E}-07$ & 0.0000 & $2.19 \mathrm{E}-06$ & 0.0000 \\
\hline$\alpha$ & 0.077648 & 0.0000 & 0.055192 & 0.0000 & 0.104885 & 0.0000 \\
\hline$\beta$ & 0.912645 & 0.0000 & 0.937484 & 0.0000 & 0.883949 & 0.0000 \\
\hline \multicolumn{7}{|l|}{ SPAS5OTR } \\
\hline$\omega$ & $2.12 \mathrm{E}-06$ & 0.0000 & $2.23 \mathrm{E}-06$ & 0.0001 & $2.07 \mathrm{E}-06$ & 0.0014 \\
\hline$\alpha$ & 0.070389 & 0.0000 & 0.067412 & 0.0000 & 0.073405 & 0.0000 \\
\hline$\beta$ & 0.919484 & 0.0000 & 0.921062 & 0.0000 & 0.916975 & 0.0000 \\
\hline \multicolumn{7}{|l|}{ SPEU } \\
\hline$\omega$ & $2.19 \mathrm{E}-06$ & 0.0000 & $1.65 \mathrm{E}-06$ & 0.0000 & $5.12 \mathrm{E}-\mathrm{o6}$ & 0.0000 \\
\hline$\alpha$ & 0.090499 & 0.0000 & 0.081063 & 0.0000 & 0.103559 & 0.0000 \\
\hline$\beta$ & 0.899012 & 0.0000 & 0.907631 & 0.0000 & 0.876888 & 0.0000 \\
\hline \multicolumn{7}{|l|}{ BRENT } \\
\hline$\omega$ & $3 \cdot 37 \mathrm{E}-06$ & 0.0001 & $2.86 \mathrm{E}-\mathrm{O} 5$ & 0.0000 & $1.68 \mathrm{E}-06$ & 0.0251 \\
\hline$\alpha$ & 0.049777 & 0.0000 & 0.071965 & 0.0000 & 0.048066 & 0.0000 \\
\hline$\beta$ & 0.944353 & 0.0000 & 0.873682 & 0.0000 & 0.948523 & 0.0000 \\
\hline \multicolumn{7}{|l|}{ US policy } \\
\hline$\omega$ & 0.000425 & 0.1169 & 0.016692 & 0.0641 & 0.046114 & 0.0536 \\
\hline$\alpha$ & 0.012532 & 0.0000 & 0.023601 & 0.0032 & 0.059857 & 0.0071 \\
\hline$\beta$ & 0.986239 & 0.0000 & 0.938191 & 0.0000 & 0.729165 & 0.0000 \\
\hline \multicolumn{7}{|l|}{ FFR } \\
\hline$\omega$ & $7.88 \mathrm{E}-06$ & 0.0000 & 1.77 E-05 & 0.0000 & 0.003067 & 0.0000 \\
\hline$\alpha$ & 0.361747 & 0.0000 & 0.434406 & 0.0000 & 0.470331 & 0.0000 \\
\hline$\beta$ & 0.794757 & 0.0000 & 0.704883 & 0.0000 & 0.333335 & 0.0000 \\
\hline \multicolumn{7}{|l|}{ VIX } \\
\hline$\omega$ & 0.000197 & 0.0000 & 0.000130 & 0.0000 & 0.000429 & 0.0000 \\
\hline$\alpha$ & 0.080543 & 0.0000 & 0.062313 & 0.0000 & 0.106429 & 0.0000 \\
\hline$\beta$ & 0.866941 & 0.0000 & 0.896518 & 0.0000 & 0.801224 & 0.0000 \\
\hline
\end{tabular}

Note: The variance equation is $\sigma_{t}^{2}=\omega+\alpha u_{t-1}^{2}+\beta \sigma_{t-1}^{2}$ in which $\alpha$ is the ARCH effect and $\beta$ is the GARCH effect. 
period. Nevertheless of the period, the degree of persistence for BRENT and VIX is considerably higher than that for US variables in the in- and post-crisis period.

Larger values for the ARCH and GARCH parameters increase the conditional volatility in different ways. The larger ARCH parameter implies that the effects of a shock are more pronounced in the subsequent period. In contrast, the larger GARCH parameter implies that the effects of a shock are more persistent (Enders, 2004). Therefore, while the larger ARCH parameter implies high short-run volatility, the larger GARCH parameter indicates high long-run volatility. The results show that the volatility processes of the Islamic and conventional equity markets are dominated by the GARCH effect. This finding implies that the conditional variance displays more autoregressive persistence, which supports the evidence found for the long-run volatility in the returns (Nazlioglu et al., 2013). This raises the question of whether the long-run volatility spills over between the stock markets. To this end, we continue our empirical analysis by conducting the test for the causality-in- variance or the volatility spillover.

The results for the volatility spillover test are illustrated in Table 4. For the four stock markets, the results for the full sample and the two sub-periods, the null hypothesis of no volatility spillover from the global markets to DJIM and from DJIM to global markets is rejected. This result thus indicates a feedback in risk between the Islamic and conventional equity markets. Thereby, we explore the risk transfer between the Islamic equity market (DJIM) and three conventional equity markets (SP500, SPAS50TR, and SPEU) in both the pre- and the in- and post-crisis periods. This finding clearly shows that the Islamic equity market is one of the viable investment venues for investors when they perceive higher risk/volatility in the global conventional markets. Therefore, investors take into account the Islamic financial markets in the portfolio diversification. This probably explains the phenomenal growth in the Islamic finance industry in the last five years since the global financial crisis. On the other hand, the risk transmission mechanism between DJIM and the global factors indicates that while the null hypothesis of no volatility spillover from the global variables to DJIM is rejected in all sample periods, it cannot be rejected when we consider the volatility spillover from DJIM to the global variables in the in- and post-crisis periods. 
Table 4: Result for the volatility spillover test

\begin{tabular}{|c|c|c|c|c|}
\hline \multirow[b]{2}{*}{ Panel A: Full sample } & \multicolumn{2}{|c|}{ pillover to DJIM } & \multicolumn{2}{|c|}{ spillover from DJIM } \\
\hline & LM-stat & $\mathrm{p}$-value & LM-stat & $\mathrm{p}$-value \\
\hline $\mathrm{SP}_{500}$ & $36.3194^{* * *}$ & 0.0000 & $15 \cdot 5173^{* * *}$ & 0.0004 \\
\hline SPAS50TR & $27.3484^{* * *}$ & 0.0000 & $101.5025^{* * *}$ & 0.0000 \\
\hline SPEU & $28.6391^{* * *}$ & 0.0000 & $23.5853^{* * *}$ & 0.0000 \\
\hline BRENT & $26.1817^{* * *}$ & 0.0000 & $14.2860^{* * *}$ & 0.0008 \\
\hline US_Policy & $26.3215^{* * *}$ & 0.0000 & 2.4770 & 0.2898 \\
\hline FFR & $41.0822^{* * *}$ & 0.0000 & 1.2479 & 0.5358 \\
\hline VIX & $35.8476^{* * *}$ & 0.0000 & $5 \cdot 3815$ & 0.0678 \\
\hline \multicolumn{5}{|l|}{$\begin{array}{c}\text { Panel B: Subsample-I } \\
\text { O4 January } 1999 \\
\text { 31 December } 2007 \\
\end{array}$} \\
\hline SP500 & $17.4338^{* * *}$ & 0.0002 & $12.6309^{* * *}$ & 0.0018 \\
\hline SPAS5OTR & $18.5569^{* * *}$ & 0.0001 & $195.0717^{* * *}$ & 0.0000 \\
\hline SPEU & $19.1819^{* * *}$ & 0.0001 & $8.7815^{* *}$ & 0.0124 \\
\hline BRENT & $16.3055^{* * *}$ & 0.0003 & $15.4508^{* * *}$ & 0.0004 \\
\hline US_Policy & $16.3069^{* * *}$ & 0.0003 & 3.5519 & 0.1693 \\
\hline FFR & $36.9818^{* * *}$ & 0.0000 & $5.0039^{*}$ & 0.0819 \\
\hline VIX & $21.0707^{* * *}$ & 0.0000 & 4.3799 & 0.1119 \\
\hline \multicolumn{5}{|l|}{$\begin{array}{c}\text { Panel C: Subsample-II } \\
\text { O1 January } 2008 \\
\text { 20 September } 2013 \\
\end{array}$} \\
\hline $\mathrm{SP}_{500}$ & $20.02053^{* * *}$ & 0.0000 & $5 \cdot 523555^{*}$ & 0.0632 \\
\hline SPAS5OTR & $10.94973^{* * *}$ & 0.0042 & $29.90917^{* * *}$ & 0.0000 \\
\hline SPEU & $11.55843^{* * *}$ & 0.0031 & $16.25239^{* * *}$ & 0.0003 \\
\hline BRENT & $11.54250^{* * * *}$ & 0.0031 & $6.713405^{* *}$ & 0.0348 \\
\hline US_Policy & $11.24912^{* * *}$ & 0.0036 & 0.843514 & 0.6559 \\
\hline FFR & $19.28524^{* * *}$ & 0.0001 & 4.335498 & 0.1144 \\
\hline VIX & $16.67045^{* * *}$ & 0.0002 & 4.085540 & 0.1297 \\
\hline
\end{tabular}

***, **, and * indicate respectively statistical significance at the 1,5 , and 10 percent levels.

From the causality-in-variance/volatility spillover test, we can say that there is a risk transfer and hence a contagion between the global conventional equity markets and the Islamic equity. Thus, our findings contrast with the argument that Islamic equity markets are not supposed to transmit risk and volatility to and from conventional equity markets because they are fundamentally different (Dridi and Hassan, 2010; Chapra, 2008; Dewi and Ferdian, 2010). The findings are also insightful to better discern how the Islamic market volatility responds to the shocks from the global influential factors.

To distinguish how the variables of interest respond to short-run temporary shocks, we can utilize the volatility impulse-response functions. To this end, we benefit from the flexibility of the 
generalized impulse-response functions ${ }^{3}$ which are derived from the VAR models ${ }^{4}$ for the pre-and the in- and post-crisis periods. The impulse-response functions of the variance (volatility) series to one standard deviation shock in the variance are presented in Figure 2 for the - pre-crisis period and in Figure 3 for the in and post-crisis period. It is worth noting here that we do not include the FFR in the VAR estimations for the pre-crisis period because it does not satisfy the stability conditions for the GARCH model.

First of all, although the impulse-response functions show similar patterns in the two periods, they show more volatility and short-lived structure in the in- and post-crisis period, implying that investors transfer risk perceptions more quickly among the equity markets after the global crisis. The responses of DJIM to shocks from $\mathrm{SP}_{5} 00$ and SPEU are significant before and the in- and post crisis period. On the other hand, even though DJIM does not significantly respond to SPAS50TR in the precrisis period, its response to a shock from SPAS50TR turns out to be significant in the in- and postcrisis period. The Asian market has a more developed Islamic finance structure in countries like Malaysia and Indonesia. Thereby, it is likely to conclude that the behavior of volatility transmission between the Islamic equity and the conventional stock markets has considerably changed in the in- and post-crisis period. For the global variables, while the responses of DJIM to shocks from BRENT and the U.S. economic policy uncertainty appear to be insignificant in both the pre- and the in- and postcrisis period, the DJIM positively responds to the VIX shocks.

\footnotetext{
${ }^{3}$ The generalized impulse response functions are not sensitive to the ordering of variables in the vector autoregression (VAR) system, and thereby the results overcome the ordering problem in the Chelosky decomposition.

${ }^{4}$ In order to satisfy the no-serial correlation and stability condition properties (the roots of the VAR model are within the unit circle), the optimal lag lengths in the VAR system are determined by general-to-specific approach.
} 

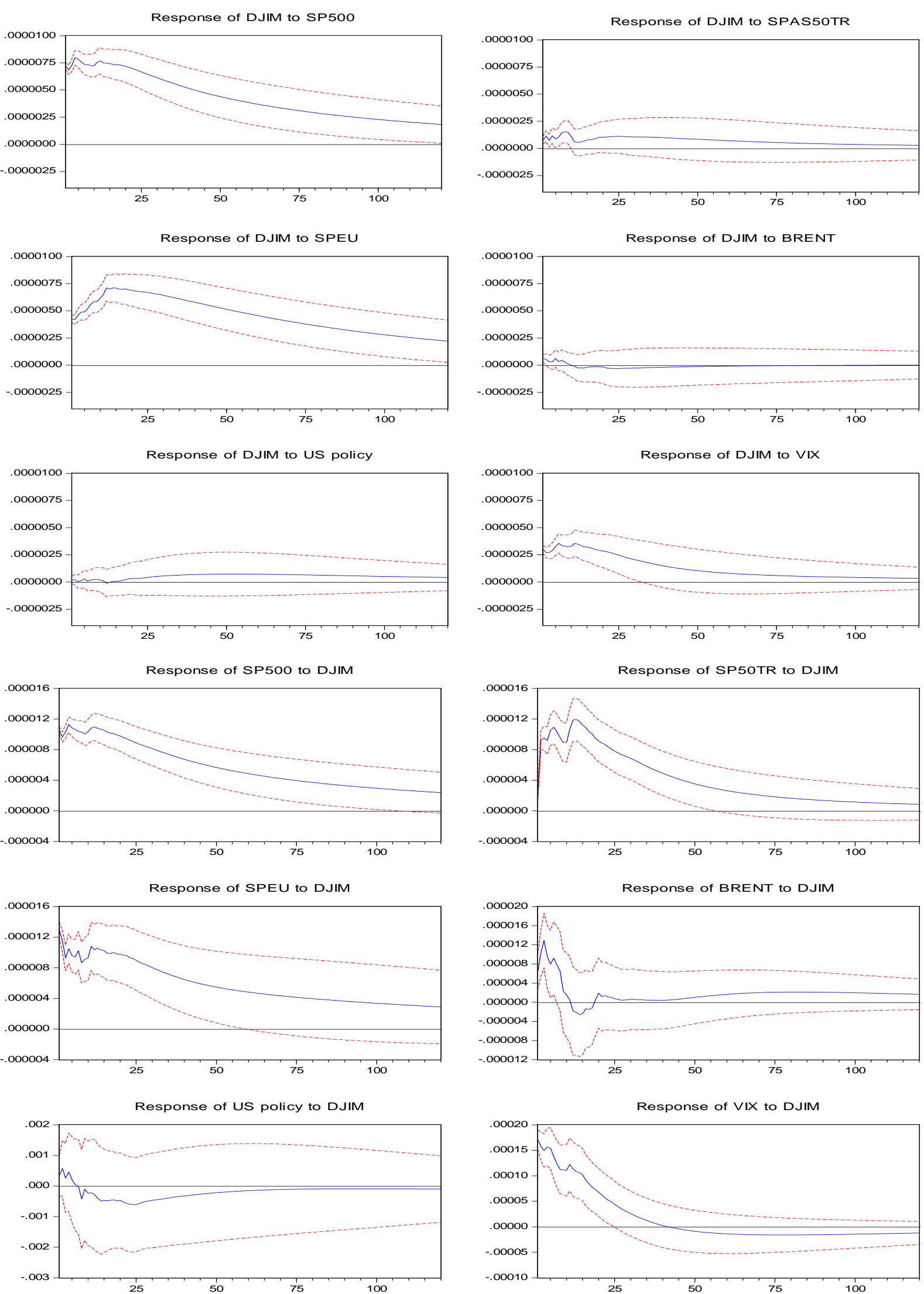

Figure 2: Volatility generalized impulse-response functions for the pre-crisis period 

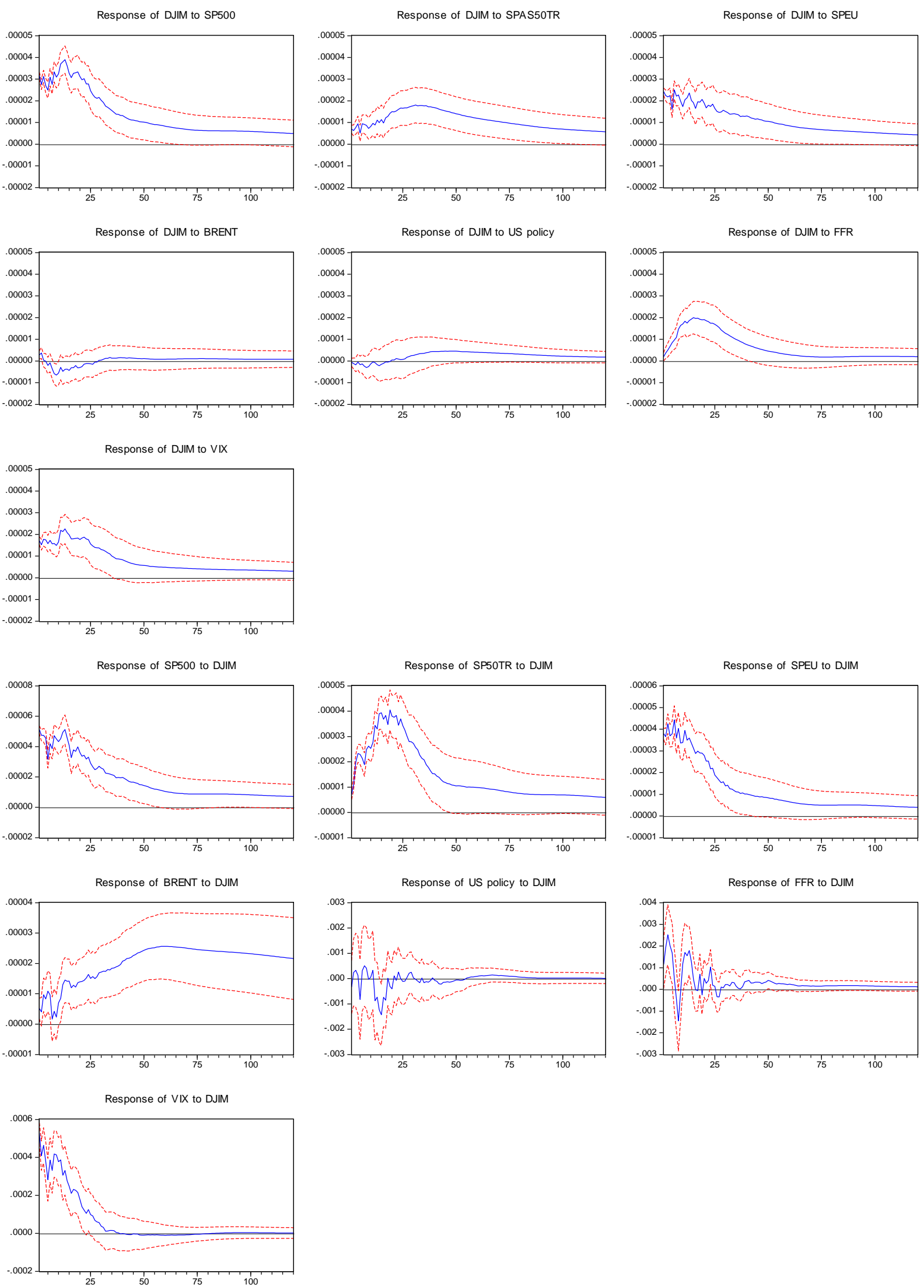

Figure 3: Volatility generalized impulse-response functions for the in- and post-crisis period 
When we consider the impacts of a shock from DJIM on the conventional markets and the global variables, at a first look, it is clear that DJIM has significant impacts on the conventional equity markets in both crisis periods. With respect to the global variables, it appears that the Islamic equity market' shocks significantly affect BRENT and VIX in the two periods. However, the impulse-response functions fail to show a significant response of the U.S. variables to a shock from the Islamic equity markets.

\section{Conclusions}

This paper examines empirically the volatility spillover between the Dow Jones Islamic equity market (DJIM) and three major global conventional equity markets (the US, European, and Asia) over the pre- and the in- and post-2008 crisis periods. It conducts the causality-in-variance (volatility spillover) test developed by Hafner and Herwartz (2006) and the generalized impulse-response functions. We first estimate the volatility models by employing the GARCH method. We find out that while the risk process of the equity markets is dominated by short-run volatility in the pre-crisis period, it is dominated by high long-run volatility in the in- and post-crisis period. It implies that volatility associated with turmoil and crises lasts longer than those linked to tranquil period. The volatility spillover test also supports that there is volatility/risk transfer between the Islamic equity market and the three major global conventional equity markets. This works against the finding in the existing literature that the Islamic markets are decoupled from their conventional counterparts.

In order to examine the responsiveness of the transmission mechanisms of the four equity markets to short-run temporary shocks, we derive the generalized volatility impulse response functions. The results indicate that the volatility transmission mechanism follows a similar pattern in both sub-periods, although it is characterized by a more volatile and short-lived structure in the second period.

The empirical evidence implies that there is a mutual risk transmission between the Islamic and conventional stock markets, signifying the presence of contagion which has continued unaffected by the global financial crisis. This finding flies in the face of the literature that looks at the Islamic equity market as a safe haven during crises. It also implies that the Sharia-based principles do not make the 
Islamic financial market much different from its conventional counterparts. This begs the question: how Islamic are the Islamic markets? The contagion effect also casts doubts on the diversification gains from including the Islamic stocks with the conventional ones in diversified portfolios. The Islamic and conventional markets are responsive to volatility and fear in the U.S. stock equity market (VIX) but not to the U.S. economic policy uncertainty, the US monetary policy (FFR), and the oil prices. This result also confirms the first finding regarding the close similarities between those markets particularly when it comes to the news-based economic uncertainty.

It is worth noting that we concentrate on analyzing bivariate volatility spillover causality in this study. Determining the nature of causal linkages between the Islamic and conventional financial markets provides room to account for other variables which affect the behavior of those stock markets. Future studies can thereby consider the risk transfer by utilizing the causality-in-variance tests and the impulse response functions based within multivariate models. Nevertheless, we assume herein that the impact of a positive volatility shock is similar to that of a negative volatility shock, and thereby we do not consider the asymmetric causal volatility linkages for the positive and negative shocks. The asymmetry can be considered as the natural behavior of financial series due to the fact that global investors react more strongly to negative than positive shocks. Therefore, future studies can also consider asymmetric causal linkages between the Islamic and conventional finance markets.

\section{References}

Akhtar, S. M., Jahromi, M., John, K. and Moise, C. E.(2013). Intensity of Volatility Linkages in Islamic and Conventional Markets. AFA 2012 Chicago Meetings Paper. Available at SSRN: http://ssrn.com/abstract=1782220 or http://dx.doi.org/10.2139/ssrn.1782220.

Akhtar, S. M., Jahromi, M., John, K. and Moise, C. E. (2013). Intensity of Volatility Linkages in Islamic and Conventional Markets. AFA 2012 Chicago Meetings Paper. Available at SSRN: http://ssrn.com/abstract=1782220 or http://dx.doi.org/10.2139/ssrn.1782220.

Andersen, T. G., Bollerslev, T., Diebold, F. X. and Vega, C. (2005). Real-time Price Discovery in Global Stock, Bond and Foreign Exchange Markets, Journal of International Economics, 73, 251-277.

Baker, S.R., Bloom, N. and Davis, S. J. (2013), Measuring Economic Policy Uncertainty, Available for download from: www.PolicyUncertainty.com.

Cappiello, L., Engle, R. and Sheppard. K. (2006), Asymmetric Dynamics in the Correlations of Global Equity and Bond Returns, Journal of Financial Econometrics, 4(4), 537-572. 
Chapra, M. U. (2008). The global financial crisis: can Islamic finance help minimize the severity and frequency of such a crisis in the future? Paper presented at the Forum on the Global Financial Crisis, Islamic Development Bank, Jeddah.

Chau, F., Deesomsak, R. and Wang, J. (2013). Political uncertainty and stock market volatility in the Middle East and North African (MENA) countries, Journal of International Financial Institution, Market and Money, 28, 1-19.

Cheung, Y.W. and Ng, L.K. (1996) A causality in variance test and its application to financial market prices. Journal of Econometrics, 72 (1-2), 33-48.

Dewi M. and Ferdian. I. R. (2010). Islamic finance: A therapy for healing the global financial crisis, http://ebookpdf. Net/islamic-finance-a-therapy-for-healing-the-global-financial-crisis.html, accessed on $10 / 04 / 2012$.

Dickey, D.A. and Fuller, W.A. (1979). Distribution of the estimators for autoregressive time series with a unit root. Journal of the American Statistical Society, 75, 427-431.

Dridi, J. and Hassan, M. (2010). The effects of global crisis on Islamic and conventional banks: A comparative study, International Monetary Fund Working Paper No, 10/201.

Elliott, G., Rothenberg, T.J. and Stock, J.H. (1996). Efficient tests for an autoregressive unit root. Econometrica, 64, 813-836.

Enders, W. (2004). Applied Econometric Time Series. $2^{\text {nd }}$ ed. John Wiley \& Sons Inc. USA.

Fang, V., Lin, C.T. and Lee, V. (2007). Volatility Linkages and Spillovers in Stock and Bond Markets: Some International Evidence, Journal of International Finance and Economics, 7(1), 1-10.

Fleming, J., Kirby, C. and Ostdiek, B. (1998). Information and Volatility Linkages in the Stock, Bond, and Money Markets, Journal of Financial Economics, 49(1), 111-137.

Hafner, C.M. and Herwartz, H. (2006). A Lagrange multiplier test for causality in variance. Economics Letters, 93 (1), 137-141.

Hammoudeh, S., Jawadi, F. and Sarafrazi. (2013). Interactions between conventional and Islamic stock markets: A hybrid threshold analysis. Memo, Drexel University, Philadelphia, PA.

Hong, Y. (2001). A test for volatility spillover with application to exchange rates. Journal of Econometrics, 103, 183-224.

Kassab. S. (2013). Modeling volatility stock market using the ARCH and GARCH models: comparative study index (SP Sharia VS SP 500), European Journal of Banking and Finance, 10, 72-77.

Kim, H-B. and Kang, S. H. (2012). Volatility Transmission between the Sharia Stock and Sukuk GII Markets in Malaysia.

http://search.yahoo.com/search; ylt=AuynaOiNRkSG9bf6F4qvcFebvZx4?p=volatility\%2C+causality + and + Islamic + markets\&toggle $=1 \& c o p=$ mss\&ei $=U T F-8 \& f r=y f p-t-900$

Kim, S. J., Moshirian, B.M. and Wu, E. (2006). Evolution of International Stock and Bond Market Integration: Influence of the European Monetary Union, Journal of Banking and Finance, 30(5), 1507-1534.

Kim, S., In, F. and Viney, C. (2001). Modelling Linkages between Australian Financial Futures Markets, Australian Journal of Management, 26(1), 19-34. 
Koop, G., Pesaran, M.H. and Potter, S.M. (1996). Impulse response analysis in nonlinear multivariate models. Journal of Econometrics, 74, 119-147.

Nazlioglu, S., Erdem, C. and Soytas, U. (2013). Volatility spillover between oil and agricultural commodity markets. Energy Economics, 36(1), 658-665.

Pesaran, M.H. and Shin, Y. (1998). Generalized impulse response analysis in linear multivariate models. Economics Letters, 58, 17-29.

Rehman, A.A. (2009). The Relevance of Islamic Finance Principles to The Global Financial Crisis, Panel Discussion on The Evolution of The Global Financial Crisis from The Current Crisis, Harvard Law School, Islamic Legal Studies Program Islamic Finance Project. Avaliable at: http://ifp.law.harvard.edu/login/view_pdf/?file=Aamir_Rehman.pdf\&type=workshops

Steeley, J. M. (2006). Volatility Transmission between the Stock and Bond Markets, International Financial Markets, Institution and Money, 16, 71-86.

Vizcaino, B. (2013). ICD launches numerical studies of Islamic finance. Available at http://finance.yahoo.com/news/icd-launches-numerical-studies-islamico73741882.html;_ylt=A2KJ3CTEKoFSdjkAAuDQtDMD

Yusof, R.M. and Majid, M. S. A. (2007). Stock Market Volatility Transmission in Malaysia: Islamic Versus Conventional Stock Market. J.KAU: Islamic Economics, 20, 17-35. 